\title{
Association analyses for dopamine receptor gene polymorphisms and weight status in a longitudinal analysis in obese children before and after lifestyle intervention
}

Christian L Roth ${ }^{1 *+}$, Anke Hinney ${ }^{2+}$, Ellen A Schur ${ }^{3}$, Clinton T Elfers ${ }^{1}$ and Thomas Reinehr ${ }^{4}$

\begin{abstract}
Background: Dopamine receptors are involved in midbrain reward circuit activation. Polymorphisms in two dopamine receptor genes, DRD2 and DRD4, have been associated with altered perception of food reward and weight gain. The objective of this study was to determine whether the same risk alleles were associated with overweight/obesity and with lower reduction of overweight after a 1-year lifestyle intervention.
\end{abstract}

Methods: In a longitudinal study the association of polymorphisms in DRD2 (rs18000497, risk allele: T, formerly A1 allele at the Taql A1 polymorphism) and DRD4 (variable number of tandem repeats (VNTR); 48 bp repeat in exon III; risk alleles: 7 repeats or longer: 7R+) was tested on weight loss success following a 1-year lifestyle childhood obesity intervention (OBELDICKS). An additional exploratory cross-sectional case-control study was performed to compare the same DRD polymorphisms in these overweight/obese children and adolescents versus lean adult controls. Subjects were 423 obese and 28 overweight children participating in lifestyle intervention (203 males), age median 12.0 (interquartile range 10.0-13.7) years, body mass index - standard deviation score (BMI-SDS) 2.4 \pm 0.5; 583 lean adults (232 males); age median 25.3 (interquartile range 22.5-26.8) years, BMI $19.1 \pm 1.9 \mathrm{~kg} / \mathrm{m}^{2}$. BMI, BMI-SDS and skinfold thickness measures were assessed at baseline and after 1 year; genotyping was performed for DRD2 risk variant rs1800497 and DRD4 exon III VNTR.

Results: The DRD2 genotype had a nominal effect on success in the weight loss intervention. The weakest BMI-SDS reduction was in children homozygous for two rs 1800497 T-alleles $(n=11)$ compared to the combined group with zero $(n=308)$ or one $(n=132)$ rs 1800497 T-allele $(-0.08 \pm 0.36$ vs. $-0.28 \pm 0.34 ; p<0.05)$. There was no association between the DRD4 VNTR alleles and genotypes and success in the weight loss intervention. No associations of the risk alleles of the DRD2 and DRD4 polymorphisms and obesity were observed in the cross-sectional part of the study.

Conclusions: We did not find association between polymorphisms in DRD2 and DRD4 genes and weight status. However, obese carriers of two DRD2 rs1800497 T-alleles may be at risk for weak responses to lifestyle interventions aimed at weight reduction.

Trial registration: Obesity intervention program "Obeldicks" is registered at clinicaltrials.gov (NCT00435734).

Keywords: Dopamine receptor polymorphisms, Obesity, Lifestyle intervention, Weight reduction

\footnotetext{
* Correspondence: christian.roth@seattlechildrens.org

${ }^{\dagger}$ Equal contributors

'Department of Pediatrics, University of Washington, Seattle Children's

Research Institute, 1900 Ninth Ave, Seattle, WA 98101, USA

Full list of author information is available at the end of the article
} 


\section{Background}

Genetic factors are involved in individual body weight variation. Midbrain dopamine circuits may play an important role in both addiction and normal eating behavior as they are involved in reward processing, particularly dopaminergic signaling via dopamine receptors 2 and 4 (DRD2, DRD4) [1-3].

Dopamine signaling plays a critical role in the striatum, a brain area that is critically involved in reward and central satiety signaling [4]. In addition, the nucleus accumbens (NAc) and its dopaminergic input from the ventrotegmental area (VTA) have been implicated in rewardseeking behavior, including enabling motor movement towards a reward [5]. These areas are part of a hunger mediating network that includes areas such as the insula, VTA, NAc and anterior cingulate cortex (ACC), which are more active during hunger and fasting and motivate consumption of calorically-dense foods [4,6-8].

Overweight individuals show increased attention to palatable food and find it more rewarding [9]. It is has been suggested that obese individuals tend to overeat in order to compensate for a weak activation of the mesolimbic reward system in response to food intake [10,11]. This could be a consequence of high fat and high carbohydrate intake. However, it is also possible that altered dopamine signaling is a risk factor for development of obesity and thus being a cause rather than a consequence of obesity. The concept of altered reward sensitivity has also been discussed in the context of binge eating disorders, substance addiction, and impulsivity [1]. Obese individuals may show hypofunctioning of food reward circuitry while resting, but hyperfunctioning when exposed to food or food cues [12,13]. However, the role of dopamine, a primary component of reward pathways, in obesity is still controversial [14-16].

Evidence suggests that dopamine-related genes moderate reward circuitry in anticipation or response to food intake. The most commonly tested and referred to DRD2 polymorphism is rs1800497 (the risk allele T is also known as the TaqI A1 allele), which was later shown to lie within the adjacent ankyrin repeat and kinase domain containing 1 gene $(A N K K 1)$ [17]. In humans a low DRD2 density is associated with the rs1800497 T-allele [18], putatively making individuals less sensitive to the activation of dopamine-based reward circuitry and rendering them more likely to overeat. In fact, binge eating has been shown to be more frequent among obese adults who were homo- or heterozygous for the T allele at rs1800497 [19].

Additional evidence implicates DRD4 signaling in reward sensitivity. DRD4 is a postsynaptic receptor that is principally inhibitory of the second messenger adenylate cyclase. DRD4s are predominantly localized in areas that are innervated by mesocortical projections from the ventral tegmental area, including the prefrontal cortex, cingulate gyrus, and insula [20]. The DRD4 exon III variable number tandem repeat " 7 repeats or longer" allele $(D R D 47 \mathrm{R}+)$ has been linked to deficient dopamine functioning [20,21].

In functional neuroimaging studies Stice et al. showed that blunted post-meal dorsal striatal activation in carriers of at least one DRD2 rs1800497 T or DRD4 7R + allele(s) was associated with stronger body mass index (BMI) increase in future $[9,22]$. Therefore we focused on these two variants in children. The question is whether gene variants of dopamine receptors moderate treatment responses and predict success in an obesity intervention based on behavioral modification. There are no studies in children investigating the effect of dopamine receptor risk alleles on outcomes of obesity intervention.

In this study, we genotyped DRD2 rs1800497 and DRD4 variable number of tandem repeats (VNTR) in overweight and obese children who underwent a lifestyle intervention, as well as in a lean adult control group. We hypothesized, that the presence of DRD2 rs1800497 T and/or DRD4 $7 \mathrm{R}$ + alleles are more frequent among overweight/ obese vs. lean subjects and are associated with weaker reduction of overweight after a 1 year childhood obesity intervention.

\section{Methods}

\section{Study groups}

Study group 1 (cases) comprised 28 overweight and 423 obese children (see Table 1; 203 males, age median $12.0 \mathrm{y}$, interquartile range 10.0 - $13.7 \mathrm{y}$, for all 451 studied children), who participated in a structured lifestyle intervention program (Obeldicks). These children were examined at the outpatient obesity referral centers in Datteln, Germany. Children with syndromal obesity, diabetes mellitus or other endocrine or psychiatric disorders were excluded from the study. Study group 2 (controls) comprised 583 German normal and underweight healthy young adult controls (see Table 1; 231 males; age median 25.3, interquartile range 22.5 - $26.8 \mathrm{y}$, for details see [23]). Their median BMI was 18.6 (interquartile range 17.7 20.6) $\mathrm{kg} / \mathrm{m}^{2}$. The study was approved by the institutional ethics committees of the Universities Witten/Herdecke and Duisburg-Essen. Written informed consent was obtained from all children and, in case of minors, their parents in accordance with institutional guidelines and with the Declaration of Helsinki.

\section{Anthropometric data and obesity related measures}

Body weight of patients and controls was evaluated using the following BMI calculation: BMI = weight $[\mathrm{kg}] /$ height $^{2}$ $\left[\mathrm{m}^{2}\right]$. In children this was expressed as a standard deviation score (BMI-SDS) (see statistical methods). Overweight and obesity were defined according to the International Task Force of Obesity by BMI-SDS between the $90^{\text {th }}$ and $97^{\text {th }}$ 
Table 1 Association of DRD2/ANKK1 rs1800497 genotypes to baseline parameters and outcomes of a weight loss intervention among overweight/obese children $(\mathrm{N}=451)$

\begin{tabular}{|c|c|c|c|c|c|c|c|}
\hline & CC (A2/A2) & CT (A1/A2) & $\mathrm{TT}(\mathrm{A} 1 / \mathrm{A} 1)$ & CC\&CT & Additive $^{a}$ & Recessive (T) & Dominant $(\mathrm{T})$ \\
\hline $\mathbf{N}$ & 308 & 132 & 11 & 440 & & & \\
\hline Baseline $\mathrm{BMI}^{\mathrm{b}}$ & $27.45 \pm 4.49$ & $27.19 \pm 4.42$ & $26.49 \pm 2.45$ & $27.38 \pm 4.46$ & 0.686 & 0.197 & 0.561 \\
\hline Change in $\mathrm{BMI}^{\mathrm{b}, \mathrm{e}}$ & $-0.41 \pm 1.95$ & $-0.99 \pm 1.93$ & $0.75 \pm 2.51$ & $-0.58 \pm 1.96$ & 0.002 & 0.023 & 0.024 \\
\hline Baseline BMI-SDS ${ }^{c}$ & $2.37 \pm 0.50$ & $2.35 \pm 0.48$ & $2.13 \pm 0.38$ & $2.36 \pm 0.50$ & 0.285 & 0.125 & 0.460 \\
\hline Change in BMI-SDS ${ }^{\mathrm{c}, e}$ & $-0.26 \pm 0.34$ & $-0.34 \pm 0.33$ & $-0.08 \pm 0.36$ & $-0.28 \pm 0.34$ & 0.015 & 0.060 & 0.090 \\
\hline Baseline triceps skinfold $(\mathrm{mm})^{\mathrm{b}, \mathrm{d}}$ & $31.29 \pm 8.80$ & $31.28 \pm 11.22$ & $32.05 \pm 6.25$ & $31.29 \pm 9.55$ & 0.966 & 0.932 & 0.850 \\
\hline Change in triceps skinfold $(\mathrm{mm})^{\mathrm{b}, \mathrm{d}}$ & $-2.40 \pm 10.41$ & $-5.38 \pm 11.59$ & $-1.86 \pm 6.47$ & $-3.27 \pm 10.83$ & 0.053 & 0.639 & 0.027 \\
\hline Baseline subscapular skinfold $(\mathrm{mm})^{\mathrm{b}, \mathrm{d}}$ & $30.12 \pm 9.75$ & $29.53 \pm 11.38$ & $30.82 \pm 5.95$ & $29.95 \pm 10.25$ & 0.837 & 0.873 & 0.741 \\
\hline Change in subscapular skinfold $(\mathrm{mm})^{\mathrm{b}, \mathrm{d}}$ & $-2.71 \pm 11.05$ & $-3.24 \pm 10.67$ & $2.91 \pm 7.67$ & $-2.87 \pm 10.92$ & 0.204 & 0.086 & 0.952 \\
\hline
\end{tabular}

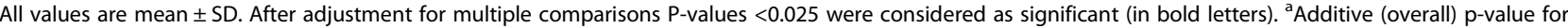
the model comparing $\mathrm{CC}, \mathrm{CT}, \mathrm{T}$.

${ }^{\mathrm{b}}$ Linear Regression P-value adjusted for age, puberty and gender. ${ }^{\mathrm{C}}$ Unadjusted linear regression P-value. ${ }^{\mathrm{d}}$ Missing values $1-4 \%$; ${ }^{\mathrm{e}}$ Missing values $5-22 \%$.

percentile and above the $97^{\text {th }}$ percentile, respectively, according to age and gender using population specific data. Height was measured to the nearest centimeter using a rigid stadiometer. Weight was measured in underwear to the nearest $0.1 \mathrm{~kg}$ using a calibrated balance scale. Height-SDS, weight-SDS and BMI-SDS were calculated according to German percentiles as mentioned in a previous study [24]. Pubertal developmental stage was assessed using the standards from Marshall and Tanner. Triceps and subscapularis skinfold thicknesses were measured in duplicate using a caliper and averaged [25].

\section{Obesity intervention}

As part of the study, all 451 children who were treated at the Vestische Kinderklinik, Datteln, participated in the 1-year German obesity intervention program "Obeldicks" which has been described previously in more detail [26] and is registered at clinicaltrials.gov (NCT00435734). Briefly, the 1-year intervention program is based on physical exercise, nutrition education, and behavioral therapy, including the individual psychological care of the child and his or her family [26]. The exercise therapy took place once per week throughout the whole intervention year.

\section{Dopamine receptor gene variants}

Blood samples were provided from all participants to extract DNA using a standard salting-out method. We genotyped the DRD2 single nucleotide polymorphism (SNP) rs1800947 as described previously [9,22]. Genotyping was performed by PCR (298 bp amplicon using the primers: forward 5'-GGCTGGCCAAGTTGTCTAAA, reverse $5^{\prime}$-CCTGAGTGTCATCAACCTCCT) and subsequent digest by TaqI; detailed conditions for the PCRRFLP can be obtained by the authors. The DRD4 exon III VNTR was genotyped as we described previously
[27]. Genotypes of 82 of the underweight controls had been used for our previously published association study [27].

\section{Statistical analysis}

Means and standard deviations were calculated for all measures, stratified by genotype. The first analysis separately examined the relationship of DRD2 rs1800497 and DRD4 VNTR to BMI in all adult and child subjects. DRD2 rs1800497 genotypes were CC, CT or TT. A combined group (CC and $\mathrm{CT}$ ) was compared to subjects who were homozygous for the rs1800497 T (risk) allele. DRD4 exon III VNTR polymorphism was classified as having no $7 \mathrm{R}+$, one $7 \mathrm{R}+$ or two $7 \mathrm{R}+$ alleles. The second analysis tested obesity intervention outcomes in obese children in relation to DRD2 and DRD4 genotypes. Longitudinal changes in BMI-SDS over the course of the 1 year "Obeldicks" program were evaluated. The rationale for testing an additive genetic model was to test the effect of zero vs. one vs. two minor alleles on BMI status and obesity intervention outcomes, which is usually the best choice if the true genetic model is not known [28]. In addition, we tested the dominant model under the assumption that one risk allele is sufficient for development of obesity and to affect obesity intervention outcomes $[9,22]$. As the genetic model is not well established for the studied variants, we finally also investigated whether two risk alleles are necessary to have an impact on BMI status and intervention outcomes in a recessive model (homozygous for the risk allele versus all other genotypes). Due to the varying distribution of BMI over different stages of childhood, the LMS method was utilized to calculate BMI-SDS as a normalized measurement for the degree of overweight. The LMS method was chosen because it summarizes the data in terms of three smooth 
age-specific curves called $L(\lambda), M(\mu)$, and $S(\sigma)$, based on German population-specific data [24,29]. The $M$ and $S$ curves correspond to the median and coefficients of variation (CVs) of BMI for German children at each age and gender, whereas the $\mathrm{L}$ curve allows for the substantial age-dependent skewness in the distribution of BMI. The assumption underlying the LMS method is that after Box-Cox power transformation, the data at each age are normally distributed [29]. We investigated the effect of the genotypes on anthropomorphic measurements both at baseline and the changes during weight intervention. Linear regression analyses were performed using Stata 12 software (Stata Corp, College Station, TX) and were calculated both unadjusted and adjusted for gender, age, puberty status and BMI-SDS as applicable. No. of risk alleles, gender, and puberty status were treated as nominal variables for all analyses. Overall effects were tested and indicator variables were used to assess the associations between risk and non-risk genotypes.

Student's t-tests were performed using Prism 5 software (GraphPad, La Jolla, CA) for two group comparisons of measurements between combined zero or one rs1800497 $\mathrm{T}$ vs. non-rs1800497 $\mathrm{T}$ alleles. All reported p-values in tables are two-sided, nominal, and are adjusted by Bonferroni correction [28] for multiple testing (2 tests: BMI status, skinfold thickness) and to confounders if stated. The consistency of genotype frequencies was tested with Hardy Weinberg equilibrium. Pearson's chi squared tests were performed using Stata 12 software (Stata Corp, College Station, TX) for comparison of DRD2 rs1800497 $\mathrm{T}$ allele and DRD4 $7 \mathrm{R}+$ allele and genotype distributions between children and lean adult controls.

\section{Results}

In longitudinal data analyses of treatment outcomes, there was an overall effect of $D R D 2$ genotype on weight loss success (Table 1). The strongest BMI and BMI-SDS reductions occurred among children with the DRD2 CT genotype. The intervention had a weak or no effect among children with TT genotypes as compared to children with no or one rs1800497 T allele (CC, CT) (Table 1, Figure 1). Of the 11 probands homozygous for the $\mathrm{T}$ allele at rs1800497, 6 were in the quartile of the weakest BMI $\mathrm{z}$-score reduction (Fisher's exact test across quartiles $\mathrm{p}=0.154$, Table 2). There was a trend in changes of subscapular skinfold thickness showing no reduction in TT vs. reduction in CC and CT (Table 1).

We detected no association of DRD4 VNTR alleles or genotypes on BMI, BMI-SDS or skinfold thickness at baseline. Nor were differences present in longitudinal changes in these parameters among the DRD4 $7 \mathrm{R}+$ allele groups (Table 3).

In the additional case control study, risk allele distribution was compared between obese children and lean

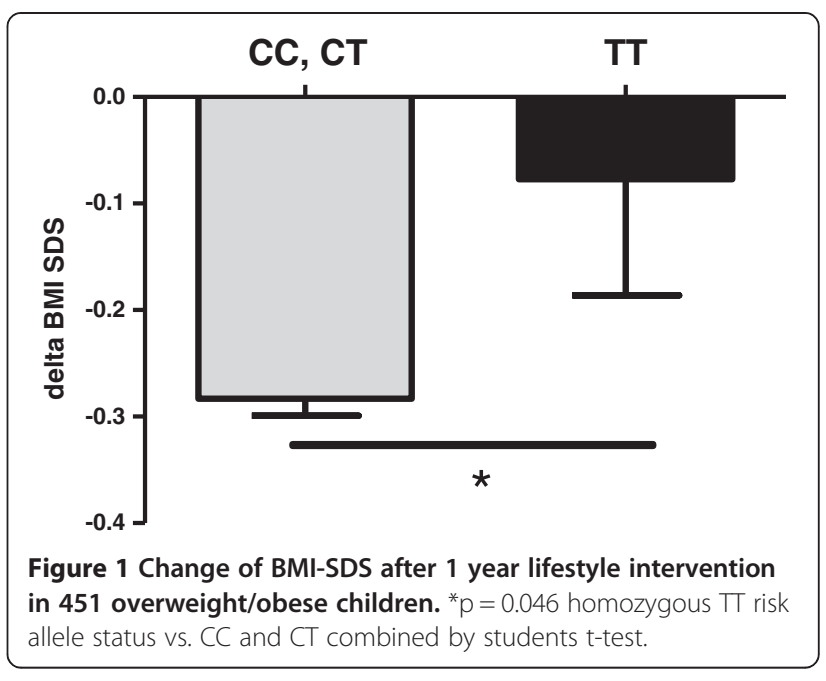

controls and there was no difference in the proportion of subjects with one (CT), two (TT), or no (CC) T alleles at rs1800497 ( $\mathrm{p}$-value $=0.840, \mathrm{x}^{2}=0.348$; Pearson's Chisquared test, see values in Table 1). Similarly, the distribution of zero, one, or two risk alleles of DRD4 7R + was not different between the obese children vs. lean controls ( $p$-value $=0.728 ; x^{2}=0.636$; Pearson's Chi-squared test) (Table 4).

\section{Discussion}

The current study examined associations between a DRD2 and a $D R D 4$ polymorphism and weight loss during a lifestyle intervention. There was an overall effect of $D R D 2$ genotype on BMI reduction in the lifestyle intervention. Homozygotes for the rs1800497 $\mathrm{T}$ allele showed a lower weight status reduction in response to lifestyle intervention than carriers of the other genotypes. There was no association of the DRD4 VNTR polymorphism with the analyzed phenotypes. This is the first report on the association of dopamine receptor variant status and childhood obesity intervention outcomes. However, in the additional cross-sectional part of the study, we did not find association for either the $D R D 2$ or the $D R D 4$ polymorphism alleles or genotypes and overweight or obesity.

We postulated that both $D R D$ gene polymorphisms evoke excessive calorie consumption, which may reflect

Table 2 Delta BMI z-score changes in quartiles vs. rs1800497T allele status, $n=\mathbf{4 4 0}$ obese children participating in lifestyle intervention

\begin{tabular}{lllll}
\hline Quartile: & $\mathbf{1}$ & $\mathbf{2}$ & $\mathbf{3}$ & $\mathbf{4}$ \\
\hline Delta BMI z-score & $-0.72 \pm 0.24$ & $-0.36 \pm 0.06$ & $-0.15 \pm 0.07$ & $0.12 \pm 0.13$ \\
CC N(\%) & $70(23.2)$ & $73(24.2)$ & $82(27.2)$ & $77(25.5)$ \\
CT N(\%) & $39(30.7)$ & $35(27.6)$ & $26(20.5)$ & $27(21.3)$ \\
$\Pi \mathrm{N}(\%)$ & $1(9.1)$ & $2(18.2)$ & $2(18.2)$ & $6(54.5)$ \\
\hline
\end{tabular}

Fisher's exact test $\mathrm{p}=0.154$. 
Table 3 Association of DRD4 exon III variable number of tandems repeat genotypes to baseline parameters and outcomes of a weight loss intervention in 451 overweight/obese children

\begin{tabular}{|c|c|c|c|c|c|c|}
\hline & No $7 \mathrm{R}+$ alleles & One $7 \mathrm{R}+$ allele & Two $7 R+$ alleles & Additive $^{a}$ & Recessive & Dominant \\
\hline $\mathbf{N}$ & 285 & 148 & 18 & & & \\
\hline Baseline BMI $^{\mathrm{b}}$ & $27.25 \pm 4.39$ & $27.41 \pm 4.58$ & $28.97 \pm 3.81$ & 0.279 & 0.355 & 0.456 \\
\hline Change in $\mathrm{BMI}^{\mathrm{b}, \mathrm{d}}$ & $-0.48 \pm 1.95$ & $-0.62 \pm 2.00$ & $-1.01 \pm 2.42$ & 0.479 & 0.434 & 0.362 \\
\hline Baseline BMI SDS ${ }^{c}$ & $2.34 \pm 0.48$ & $2.38 \pm 0.53$ & $2.5 \pm 0.3$ & 0.413 & 0.336 & 0.253 \\
\hline Change in BMI SDS $S^{c, d}$ & $-0.25 \pm 0.32$ & $-0.32 \pm 0.36$ & $-0.30 \pm 0.43$ & 0.358 & 0.746 & 0.152 \\
\hline Baseline triceps skinfold $(\mathrm{mm})^{\mathrm{b}, \mathrm{e}}$ & $31.17 \pm 9.45$ & $30.63 \pm 7.08$ & $34.82 \pm 5.11$ & 0.167 & 0.107 & 0.825 \\
\hline Change in triceps skinfold $(\mathrm{mm})^{\mathrm{b}, \mathrm{e}}$ & $-2.94 \pm 11.29$ & $-3.03 \pm 6.45$ & $-4.03 \pm 6.71$ & 0.915 & 0.867 & 0.976 \\
\hline Baseline subscapular skinfold $(\mathrm{mm})^{\mathrm{b}, \mathrm{e}}$ & $29.95 \pm 10.58$ & $29.31 \pm 8.29$ & $32.45 \pm 5.56$ & 0.440 & 0.344 & 0.776 \\
\hline Change in subscapular skinfold $(\mathrm{mm})^{\mathrm{b}, \mathrm{e}}$ & $-2.73 \pm 11.09$ & $-2.04 \pm 9.15$ & $-3.27 \pm 9.74$ & 0.805 & 0.935 & 0.573 \\
\hline
\end{tabular}

All values are mean \pm SD. ${ }^{a}$ Additive (overall) $p$-value for the model comparing 0,1 , or $>1$ repeats.

${ }^{\mathrm{b}}$ Linear Regression P-value adjusted for age, puberty and gender. ${ }^{\mathrm{C} U n a d j u s t e d ~ l i n e a r ~ r e g r e s s i o n ~ P-v a l u e . ~}{ }^{\mathrm{d}}$ Missing values $1-4 \%$; ${ }^{\mathrm{e}}$ Missing values $5-20 \%$.

overall impaired dopamine-driven response inhibition leading to obesity and poor obesity intervention outcomes [30]. Response inhibition refers to the neural process by which unnecessary or inappropriate motor action is suppressed [31-35]. Impaired response inhibition is a behavioral trait of which impaired satiety may be one manifestation. A related trait - impulsivity - has been linked to obesity [36-38] and poor obesity treatment outcomes in children [37].

In the longitudinal part of the study, gene polymorphisms in DRD2 did predict (nominal p-value $<0.05$ ) outcomes in the lifestyle intervention. Carriers of two DRD2 rs1800497 $\mathrm{T}$ alleles may be at risk for weaker weight status reduction in response to lifestyle intervention. This group seems to be enriched in lowest quartile for BMI z-score reduction (Table 2). However, these results need to be regarded with caution as they did not reach statistical significance upon Bonferroni correction. Thus, even though the number of children in this group was a small proportion of the total children enrolled, children with the TT genotype may represent a larger proportion of children who do not do well in lifestyle interventions. We did not find evidence that carriers of one rs1800497 $\mathrm{T}$ allele are at risk for obesity or reduced success during obesity intervention which needs to be discussed in context with prior results of functional neuroimaging studies by Stice et al. in which the presence of one risk allele was sufficient to modulate the relation between food reward and future weight gain [9,22]. Although the authors reported that the rs1800497 $\mathrm{T}$ (A1) allele status did not predict increase in BMI over follow-up, they found that the rs1800497 $\mathrm{T}$ allele moderated the relations of brain responses during exposure to appetizing vs. unappetizing food to risk for increases in BMI over the 1-year follow-up. Therefore, it is possible that the effects of $D R D$ variant status on neuronal activation is stronger than on weight status per se, as individuals in our study were seeking weight loss and therefore may already have compensated somewhat for this predisposition. Moreover, our data support the hypothesis that children with a single risk allele may actually be particularly responsive to lifestyle intervention as they demonstrated significantly greater reductions in BMI. Behavioral therapy and nutrition education might be sufficient to engage

Table 4 Distribution of DRD2/ANKK1 rs1800497 alleles and DRD4 exon III variable number of tandems repeat alleles in relation to $B M I$ among all adult and pediatric subjects

\begin{tabular}{|c|c|c|c|c|c|c|c|c|c|}
\hline \multicolumn{5}{|c|}{ Adults (lean) } & \multicolumn{5}{|c|}{ Children (overweight or obese) } \\
\hline & $N(\%$ of total) $n=583$ & Age & Sex & BMI & $N(\%$ of total) $n=451$ & Age & Sex & BMI & BMI-SDS \\
\hline \multicolumn{10}{|l|}{ rs1800497 } \\
\hline$C C(A 2 / A 2)$ & $407(69.8)$ & $25.4 \pm 4.5$ & $161 \mathrm{M} / 246 \mathrm{~F}$ & $19.2 \pm 2.0$ & $308(68.3)$ & $10.8 \pm 2.6$ & $139 \mathrm{M} / 169 \mathrm{~F}$ & $27.5 \pm 4.5$ & $2.4 \pm 0.5$ \\
\hline CT (A1/A2) & $161(27.6)$ & $25.1 \pm 4.3$ & $64 \mathrm{M} / 97 \mathrm{~F}$ & $19.1 \pm 1.9$ & $132(29.3)$ & $10.7 \pm 2.7$ & $60 \mathrm{M} / 72 \mathrm{~F}$ & $27.2 \pm 4.4$ & $2.3 \pm 0.5$ \\
\hline TT (A1/A1) & $15(2.6)$ & $24.4 \pm 3.0$ & $6 \mathrm{M} / 9 \mathrm{~F}$ & $18.2 \pm 1.1$ & $11(2.4)$ & $11.3 \pm 1.7$ & $4 \mathrm{M} / 7 \mathrm{~F}$ & $26.5 \pm 2.5$ & $2.1 \pm 0.4$ \\
\hline \multicolumn{10}{|l|}{ DRD4 7R+ } \\
\hline No & $357(61.2)$ & $25.6 \pm 4.6$ & $149 \mathrm{M} / 208 \mathrm{~F}$ & $19.2 \pm 2.0$ & $285(63.2)$ & $10.8 \pm 2.6$ & $135 \mathrm{M} / 150 \mathrm{~F}$ & $27.2 \pm 4.4$ & $2.3 \pm 0.5$ \\
\hline One & $198(34.0)$ & $24.8 \pm 4.1$ & $71 \mathrm{M} / 127 \mathrm{~F}$ & $19.0 \pm 1.9$ & $148(32.8)$ & $10.8 \pm 2.7$ & $62 \mathrm{M} / 86 \mathrm{~F}$ & $27.4 \pm 4.6$ & $2.4 \pm 0.5$ \\
\hline Two & $28(4.8)$ & $25.4 \pm 4.0$ & $11 \mathrm{M} / 17 \mathrm{~F}$ & $18.8 \pm 1.5$ & $18(4.0)$ & $11.4 \pm 2.1$ & $6 \mathrm{M} / 12 \mathrm{~F}$ & $29.0 \pm 3.8$ & $2.5 \pm 0.3$ \\
\hline
\end{tabular}

Age and $\mathrm{BMI}$ values are Mean \pm SD. 
cognitive control and counteract predispositions in this population, which, if our findings are replicated, would be encouraging.

Humans who are homo- or heterozygous for DRD4 $7 \mathrm{R}+$ alleles have shown higher peak body mass in cohorts at risk for obesity [39,40], greater food cravings [41], as well as smoking, alcohol, and drug cravings [42-44]. We did not find association for DRD4 7R + allele carriers to obesity, or weight loss success in a childhood obesity lifestyle intervention. In addition, there are also no published studies showing an association between $D R D 47 \mathrm{R}+$ alleles and weight status or responses to obesity intervention in this age group. Potentially this is not a predominating factor for weight status and response to obesity intervention in the age group of our studied children.

Studying children is advantageous as the obesity is not yet chronic and exposure to a calorie dense diet was not very long. Longer exposure has been hypothesized to reduce dopamine signaling via receptor down-regulation. In the additional cross-sectional part of the study, we did not find evidence that the risk alleles at the tested $D R D 2$ and DRD4 polymorphisms are associated with measures of obesity. These data are not inconsistent with prior findings, as the DRD2 rs1800497 $\mathrm{T}$ allele was associated with increased body mass in some studies [45-47], while other studies do not show association $[48,49]$. In recent a longitudinal study investigating the association between change in BMI from adolescence to young adulthood and polymorphisms in genes involved in serotonergic and dopaminergic functioning, no significant associations were found between DRD2 rs1800497 $\mathrm{T}$ allele or DRD4 7R + allele and BMI categories [50]. However, a polymorphism in the monoamine oxidase A (MAOA) gene, that encodes an enzyme that metabolizes dopamine, serotonin and noradrenaline, was associated with increased BMI which further supports that the gene variants involved in dopamine metabolism might have an impact on body weight change.

Strengths of this study include the relatively large sample size for the childhood obesity intervention and the longitudinal study design. However, limitations persist that should be discussed. First, adiposity was assessed by indirect estimations (BMI, BMI-SDS; skinfold thickness) [51]. Second, we analyzed the effects of the DRD gene polymorphisms only on anthropometric measures and were not able to include any behavioral tests or data on eating. Future studies should include assessment of eating behaviors. Third, in the exploratory cross-sectional part of our study, the lean control group consisted of young adults. Although obese children and adolescents frequently become obese adults [52] and lean adults were most likely lean children, it is possible that some of the lean adult controls were obese during childhood. However, we deem lean adults as better controls for association studies than lean children, as a proportion of the lean children might become obese adults. Hence, lean children might harbor 'obesity alleles' and therefore decrease the power of the association study. Finally, we investigated the effect of two DRD polymorphisms in our study, but other $D R D$ polymorphisms could have an impact as well $[3,50,53]$.

\section{Conclusions}

Our findings contribute to a further understanding of the relation between alterations in dopamine receptor structure and/or function that have previously been shown to lead to compromised dopamine signaling in reward brain areas and higher risk for developing obesity. Although we did not demonstrate an association between DRD4 VNTR and weight status, we found that carriers of DRD2 rs1800497 $\mathrm{T}$ alleles are at risk for weak responses to lifestyle interventions aimed at weight reduction.

\section{Abbreviations}

ACC: Anterior cingulate cortex; ANKK1: Ankyrin repeat and kinase domain containing 1; BMI: Body mass index; BMI-SDS: Body mass index - standard deviation score; CVs: Coefficients of variation; DRD2: Dopamine receptor 2; DRD4: Dopamine receptor 4; NAc: Nucleus accumbens; VNTR: Variable number of tandem repeats; VTA: Ventrotegmental area.

\section{Competing interests}

The authors declare that they have no competing interests.

\section{Authors' contributions}

$A H, T R$, and $C R$ developed the study design. $C E, E S, T R$, and $C R$ performed statistical analyses. TR performed and supervised anthropometrical measurements. AH supervised the genetic tests. CR wrote the first draft of the paper. All authors discussed the findings. All authors read and approved the final manuscript.

\section{Acknowledgments}

We thank Jitka Andrä for her excellent technical support. Thomas Reinehr, Anke Hinney and received grant support from the German Ministry of Education and Research (Bundesministerium für Bildung und Forschung: 01KU0903, Obesity network LARGE 01G10839, the National Genome Research Network, NGFNplus 01GS0820).

\section{Author details}

${ }^{1}$ Department of Pediatrics, University of Washington, Seattle Children's Research Institute, 1900 Ninth Ave, Seattle, WA 98101, USA. ²Department of Child and Adolescent Psychiatry, Universitätsklinikum Essen (AöR), University of Duisburg-Essen, Wickenburgstr, Essen 21, 45147, Germany. ${ }^{3}$ Internal Medicine, University of Washington Medical Center, 1959 NE Pacific St, Seattle, WA 98195, USA. ${ }^{4}$ Pediatric Endocrinology, Diabetes, and Nutrition Medicine, Vestische Hospital for Children and Adolescents Datteln, University of Witten/Herdecke, Dr. F. Steiner Str. 5, Datteln 45711, Germany.

Received: 10 June 2013 Accepted: 22 November 2013

Published: 27 November 2013

\section{References}

1. Doehring A, Kirchhof A, Lotsch J: Genetic diagnostics of functional variants of the human dopamine D2 receptor gene. Psychiatr Genet 2009, 19(5):259-268.

2. Chen D, Liu F, Shang Q, Song X, Miao X, Wang Z: Association between polymorphisms of DRD2 and DRD4 and opioid dependence: evidence from the current studies. Am J Med Genet B Neuropsychiatr Genet 2011, 156B(6):661-670.

3. Mignini F, Napolioni V, Codazzo C, Carpi FM, Vitali M, Romeo M, Ceccanti M: DRD2/ANKK1 TaqIA and SLC6A3 VNTR polymorphisms in alcohol 
dependence: association and gene-gene interaction study in a population of Central Italy. Neurosci Lett 2012, 522(2):103-107.

4. Mehta S, Melhorn SJ, Smeraglio A, Tyagi V, Grabowski T, Schwartz MW Schur EA: Regional brain response to visual food cues is a marker of satiety that predicts food choice. Am J Clin Nutr 2012, 96(5):989-999.

5. Nicola SM: The nucleus accumbens as part of a basal ganglia action selection circuit. Psychopharmacol (Berl) 2007, 191(3):521-550.

6. Del Parigi A, Gautier JF, Chen K, Salbe AD, Ravussin E, Reiman E, Tataranni PA: Neuroimaging and obesity: mapping the brain responses to hunger and satiation in humans using positron emission tomography. Ann N Y Acad SCl 2002, 967:389-397.

7. LaBar KS, Gitelman DR, Parrish TB, Kim YH, Nobre AC, Mesulam MM: Hunger selectively modulates corticolimbic activation to food stimuli in humans. Behav Neurosci 2001, 115(2):493-500.

8. Uher R, Treasure J, Heining M, Brammer MJ, Campbell IC: Cerebral processing of food-related stimuli: effects of fasting and gender. Behav Brain Res 2006, 169(1):111-119.

9. Stice E, Yokum S, Bohon C, Marti N, Smolen A: Reward circuitry responsivity to food predicts future increases in body mass: moderating effects of DRD2 and DRD4. Neuroimage 2010, 50(4):1618-1625.

10. Comings DE, Blum K: Reward deficiency syndrome: genetic aspects of behavioral disorders. Prog Brain Res 2000, 126:325-341.

11. Wang GJ, Volkow ND, Fowler JS: The role of dopamine in motivation for food in humans: implications for obesity. Expert Opin Ther Targets 2002, 6(5):601-609.

12. DelParigi $A$, Chen $K$, Salbe AD, Hill JO, Wing RR, Reiman EM, Tataranni PA: Persistence of abnormal neural responses to a meal in postobese individuals. Int J Obes Relat Metab Disord 2004, 28(3):370-377.

13. Stoeckel LE, Kim J, Weller RE, Cox JE, Cook EW 3rd, Horwitz B: Effective connectivity of a reward network in obese women. Brain Res Bull 2009, 79(6):388-395

14. Davis C, Fox J: Sensitivity to reward and body mass index (BMI): evidence for a non-linear relationship. Appetite 2008, 50(1):43-49.

15. Haltia LT, Rinne JO, Merisaari H, Maguire RP, Savontaus E, Helin S, Nagren K Kaasinen V: Effects of intravenous glucose on dopaminergic function in the human brain in vivo. Synapse 2007, 61(9):748-756.

16. Volkow ND, Wang GJ, Telang F, Fowler JS, Thanos PK, Logan J, Alexoff D, Ding YS, Wong C, Ma Y, et al: Low dopamine striatal D2 receptors are associated with prefrontal metabolism in obese subjects: possible contributing factors. Neuroimage 2008, 42(4):1537-1543.

17. Dubertret C, Gouya L, Hanoun N, Deybach JC, Ades J, Hamon M, Gorwood P: The $3^{\prime}$ region of the DRD2 gene is involved in genetic susceptibility to schizophrenia. Schizophr Res 2004, 67(1):75-85.

18. Ritchie T, Noble EP: Association of seven polymorphisms of the D2 dopamine receptor gene with brain receptor-binding characteristics. Neurochem Res 2003, 28(1):73-82.

19. Davis C, Levitan RD, Yilmaz Z, Kaplan AS, Carter JC, Kennedy JL: Binge eating disorder and the dopamine D2 receptor: genotypes and sub-phenotypes. Prog Neuropsychopharmacol Biol Psychiatry 2012, 38(2):328-335.

20. Noain D, Avale ME, Wedemeyer C, Calvo D, Peper M, Rubinstein M: Identification of brain neurons expressing the dopamine D4 receptor gene using BAC transgenic mice. Eur J Neurosci 2006, 24(9):2429-2438.

21. Asghari V, Sanyal S, Buchwaldt S, Paterson A, Jovanovic V, Van Tol HH: Modulation of intracellular cyclic AMP levels by different human dopamine D4 receptor variants. J Neurochem 1995, 65(3):1157-1165.

22. Stice E, Spoor S, Bohon C, Small DM: Relation between obesity and blunted striatal response to food is moderated by TaqIA A1 allele. Science 2008, 322(5900):449-452.

23. Muller TD, Tschop MH, Jarick I, Ehrlich S, Scherag S, Herpertz-Dahlmann B, Zipfel S, Herzog W, de Zwaan M, Burghardt R, et al: Genetic variation of the ghrelin activator gene ghrelin O-acyltransferase (GOAT) is associated with anorexia nervosa. J Psychiatr Res 2011, 45(5):706-711.

24. Kromeyer-Hauschild K, Wabitsch M, Geller F, et al: Percentiles of body mass index in children and adolescents evaluated from different regional German studies. Monatsschr Kinderheilkd 2001, 149:807-818.

25. Slaughter MH, Lohman TG, Boileau RA, Horswill CA, Stillman RJ, Van Loan MD, Bemben DA: Skinfold equations for estimation of body fatness in children and youth. Hum Biol 1988, 60(5):709-723.

26. Reinehr T, de Sousa G, Toschke AM, Andler W: Long-term follow-up of cardiovascular disease risk factors in children after an obesity intervention. Am J Clin Nutr 2006, 84(3):490-496.
27. Hinney A, Schneider J, Ziegler A, Lehmkuhl G, Poustka F, Schmidt MH, Mayer H, Siegfried W, Remschmidt H, Hebebrand J: No evidence for involvement of polymorphisms of the dopamine D4 receptor gene in anorexia nervosa, underweight, and obesity. Am J Med Genet 1999, 88(6):594-597.

28. Lunetta KL: Genetic association studies. Circulation 2008, 118(1):96-101.

29. Cole TJ: The LMS method for constructing normalized growth standards. Eur J Clin Nutr 1990, 44(1):45-60.

30. Ghahremani DG, Lee B, Robertson CL, Tabibnia G, Morgan AT, De Shetler N, Brown AK, Monterosso JR, Aron AR, Mandelkern MA, et al: Striatal dopamine D2/D3 receptors mediate response inhibition and related activity in frontostriatal neural circuitry in humans. J Neurosci 2012 , 32(21):7316-7324.

31. Rieger M, Gauggel S, Burmeister K: Inhibition of ongoing responses following frontal, nonfrontal, and basal ganglia lesions. Neuropsychology 2003, 17(2):272-282.

32. Aron AR, Durston S, Eagle DM, Logan GD, Stinear CM, Stuphorn V: Converging evidence for a fronto-basal-ganglia network for inhibitory control of action and cognition. J Neurosci 2007, 27(44):11860-11864.

33. Mostofsky SH, Simmonds DJ: Response inhibition and response selection: two sides of the same coin. J Cogn Neurosci 2008, 20(5):751-761.

34. Chambers CD, Garavan $\mathrm{H}$, Bellgrove MA: Insights into the neural basis of response inhibition from cognitive and clinical neuroscience. Neurosci Biobehav Rev 2009, 33(5):631-646.

35. Tabibnia G, Monterosso JR, Baicy K, Aron AR, Poldrack RA, Chakrapani S, Lee $B$, London ED: Different forms of self-control share a neurocognitive substrate. J Neurosci 2011, 31(13):4805-4810.

36. Braet C, Claus L, Verbeken S, Van Vlierberghe L: Impulsivity in overweight children. Eur Child Adolesc Psychiatry 2007, 16(8):473-483.

37. Nederkoorn C, Jansen E, Mulkens S, Jansen A: Impulsivity predicts treatment outcome in obese children. Behav Res Ther 2007, 45(5):1071-1075.

38. van den Berg L, Pieterse K, Malik JA, Luman M, Willems van Dijk K, Oosterlaan J, Delemarre-van de Waal HA: Association between impulsivity, reward responsiveness and body mass index in children. Int J Obes (Lond) 2011, 35(10):1301-1307.

39. Guo G, North KE, Gorden-Larsen P, Bulik CM, Choi S: Body mass, DRD4, physical activity, sedentary behavior, and family socioeconomic status: the add health study. Obesity (Silver Spring) 2007, 15(5):1199-1206.

40. Kaplan AS, Levitan RD, Yilmaz Z, Davis C, Tharmalingam S, Kennedy JL: A DRD4/BDNF gene-gene interaction associated with maximum BMI in women with bulimia nervosa. Int J Eat Disord 2008, 41(1):22-28.

41. Sobik L, Hutchison K, Craighead L: Cue-elicited craving for food: a fresh approach to the study of binge eating. Appetite 2005, 44(3):253-261.

42. McClernon FJ, Hutchison KE, Rose JE, Kozink RV: DRD4 VNTR polymorphism is associated with transient $\mathrm{FMRI-BOLD}$ responses to smoking cues. Psychopharmacol (Berl) 2007, 194(4):433-441.

43. Filbey FM, Ray L, Smolen A, Claus ED, Audette A, Hutchison KE: Differential neural response to alcohol priming and alcohol taste cues is associated with DRD4 VNTR and OPRM1 genotypes. Alcohol Clin Exp Res 2008 32(7):1113-1123.

44. Shao C, Li Y, Jiang K, Zhang D, Xu Y, Lin L, Wang Q, Zhao M, Jin L: Dopamine D4 receptor polymorphism modulates cue-elicited heroin craving in Chinese. Psychopharmacol (Berl) 2006, 186(2):185-190.

45. Thomas GN, Critchley JA, Tomlinson B, Cockram CS, Chan JC: Relationships between the taql polymorphism of the dopamine D2 receptor and blood pressure in hyperglycaemic and normoglycaemic Chinese subjects. Clin Endocrinol (Oxf) 2001, 55(5):605-611.

46. Fang YJ, Thomas GN, Xu ZL, Fang JQ, Critchley JA, Tomlinson B: An affected pedigree member analysis of linkage between the dopamine D2 receptor gene Taql polymorphism and obesity and hypertension. Int J Cardiol 2005, 102(1):111-116.

47. Chen AL, Blum K, Chen TJ, Giordano J, Downs BW, Han D, Barh D, Braverman ER: Correlation of the Taq1 dopamine D2 receptor gene and percent body fat in obese and screened control subjects: a preliminary report. Food Funct 2012, 3(1):40-48.

48. Jenkinson CP, Hanson R, Cray K, Wiedrich C, Knowler WC, Bogardus C, Baier L: Association of dopamine D2 receptor polymorphisms Ser311Cys and TaqIA with obesity or type 2 diabetes mellitus in Pima Indians. Int J Obes Relat Metab Disord 2000, 24(10):1233-1238.

49. Southon A, Walder K, Sanigorski AM, Zimmet P, Nicholson GC, Kotowicz MA, Collier G: The Taq IA and Ser311 Cys polymorphisms in the dopamine D2 receptor gene and obesity. Diabetes Nutr Metab 2003, 16(1):72-76. 
50. Fuemmeler BF, Agurs-Collins TD, McClernon FJ, Kollins SH, Kail ME, Bergen AW, Ashley-Koch AE: Genes implicated in serotonergic and dopaminergic functioning predict BMI categories. Obesity (Silver Spring) 2008, 16(2):348-355

51. Snijder MB, Visser M, Dekker JM, Seidell JC, Fuerst T, Tylavsky F, Cauley J, Lang T, Nevitt M, Harris TB: The prediction of visceral fat by dualenergy X-ray absorptiometry in the elderly: a comparison with computed tomography and anthropometry. Int I Obes Relat Metab Disord 2002, 26(7):984-993.

52. Whitaker RC, Wright JA, Pepe MS, Seidel KD, Dietz WH: Predicting obesity in young adulthood from childhood and parental obesity. N Eng/ I Med 1997, 337(13):869-873.

53. Esposito-Smythers C, Spirito A, Rizzo C, McGeary JE, Knopik VS: Associations of the DRD2 TaqlA polymorphism with impulsivity and substance use: preliminary results from a clinical sample of adolescents. Pharmacol Biochem Behav 2009, 93(3):306-312.

doi:10.1186/1471-2431-13-197

Cite this article as: Roth et al: Association analyses for dopamine receptor gene polymorphisms and weight status in a longitudinal analysis in obese children before and after lifestyle intervention. BMC Pediatrics 2013 13:197.

\section{Submit your next manuscript to BioMed Central and take full advantage of:}

- Convenient online submission

- Thorough peer review

- No space constraints or color figure charges

- Immediate publication on acceptance

- Inclusion in PubMed, CAS, Scopus and Google Scholar

- Research which is freely available for redistribution 